\title{
A Roadmap to Inform the Implementation of Evidence-Based Collaborative Care Interventions in Communities: Insights From the Michigan Mental Health Integration Partnership
}

\author{
Amy Rusch ( $\nabla$ amyrusch@umich.edu ) \\ University of Michigan Medical School https://orcid.org/0000-0002-3647-6946 \\ Lindsay DeCamp \\ University of Michigan \\ Celeste Liebrecht \\ University of Michigan
}

Seo Youn Choi

University of Michigan School of Public Health

Gregory W Dalack

University of Michigan Department of Psychiatry

Amy M Kilbourne

University of Michigan

Shawna N Smith

University of Michigan School of Public Health

\section{Research}

Keywords: Implementation Roadmap, Pre-Implementation, Implementation, Sustainability, Behavioral Health Services, Evidence-based, Medicaid, Collaborative Care, Implementation Science

Posted Date: November 24th, 2020

DOl: https://doi.org/10.21203/rs.3.rs-112875/v1

License: (c) (1) This work is licensed under a Creative Commons Attribution 4.0 International License. Read Full License 


\section{Abstract}

\section{Background}

In spite of increasing calls for further spread of evidence-based collaborative care interventions (EBIs) in community-based settings, practitioner-driven efforts are often stymied by a lack of experience in addressing barriers to community-based implementation, especially for those not familiar with implementation science. The Michigan Mental Health Integration Partnership (MIP) is a statewide initiative that funds projects that support implementation and uptake of EBIs in community-based settings. MIP also provides an in situ implementation laboratory for understanding barriers to the uptake of EBIs across a variety of settings. We report findings from a Statewide qualitative study of practitioners involved in MIP projects to garner their perspectives of best practices in the implementation of EBIs.

Methods

Twenty-eight semi-structured interviews of practitioners and researchers from six MIP Projects were conducted with individuals implementing various MIP EBI projects across Michigan, including stakeholders from project teams, implementation sites, and the State of Michigan, to identify common barriers, challenges, and implementation strategies deployed by the project teams, with the purpose of informing a set of implementation steps and milestones. Results

Stakeholders identified a number of barriers to and strategies for success, including the need for tailoring program deployment and implementation to specific site needs, development of web-based tools for facilitating program implementation, and the importance of upper level administration buy-in. Findings informed our resultant community-based Implementation Roadmap, which identifies critical steps across three implementation phases-pre-implementation, implementation, and sustainability-for implementation practitioners to use in their EBI implementation efforts.

\section{Conclusion}

Implementation practitioners interested in community-based EBI implementation often lack access to operationalized implementation "steps" or "best practices" that can facilitate successful uptake and evaluation. Our community-informed MIP Implementation Roadmap, offering generalized steps for reaching successful implementation, uses experiences from a diverse set of MIP teams to guide practitioners through the practices necessary for scaling up EBIs in community-based settings over preimplementation, implementation and sustainability phases.

\section{Contributions To The Literature}

- Research shows evidence-based interventions (EBIs) rarely get adopted in routine care once research ends, yet there is little practical guidance for end-users to adopt and maintain EBIs. 
- To support effective implementation for practitioners not well versed in implementation science, providing a practical roadmap of implementation processes derived from successful implementation science studies may help overcome the research-to-practice gap.

- Using data from interviews, we developed the MIP Implementation Roadmap to guide communitybased researchers in pre-implementation, implementation, and sustainability phases of early efforts to implement EBIs, improving the effectiveness of current implementation efforts and providing scaffolding for larger scale, sustainable implementation efforts.

\section{Background}

Innovative and effective evidence-based collaborative care interventions (EBIs) for addressing behavioral health concerns are being developed to serve a variety of populations and settings $(1,2)$. However, the creation of EBls does not necessarily translate into their implementation by practitioners (2-5). Often practitioners looking to implement new EBls are stymied by lack of knowledge or understanding of how to identify and address barriers to community-based implementation (6). In order to expand the use of EBIs, implementation scientists can help to fill this gap by developing and disseminating tools that can support, direct, and protocolize EBI implementation efforts by community-based practitioners.

An Implementation Roadmap that helps practitioners define and address challenges in implementing EBIs provides one potential, readily disseminateable tool for supporting EBI implementation. Implementation Roadmaps, similar to roadmaps developed in organizational studies and business communities (i.e. Technology Roadmaps) (7), provide 'scripts' for the critical steps practitioners should follow in scaling up EBIs to new settings (8-11). Established EBIs can include standardized implementation steps and implementation resources can support gerenalized EBI implementation, but few models provide specific steps and pathways to implementation across a variety of real-world settings (9-11). Implementation Roadmaps can guide process development by highlighting key steps and recommending "best practices" for use throughout the real-world implementation process. Implementation Roadmaps aim to increase the efficiency of real-world implementation efforts by outlining in advance the different stages of the implementation process, and identifying the actions practitioners might want to take to anticipate, accommodate, and/or alleviate barriers to successful EBI deployment. The Quality Enhancement Research Initiative (QUERI) Implementation Roadmap illustrates how a roadmap can act as a researcher-community implementation guide, demonstrating the utility of this tool (14). A well-designed Implementation Roadmap can help bridge the gap between implementation scientists and practitioners, by leveraging implementation science expertise to help demystify the implementation process (15-17).

To support implementation of interventions, implementation scientists have developed numerous frameworks for describing, understanding, and evaluating the implementation process. Frameworks such as the Consolidated Framework for Implementation Research (CFIR) (18), Exploration, Preparation, Implementation, Sustainment (EPIS) (19), and Reach, Effectiveness, Adoption, Implementation, and Maintenance (RE-AIM) (20), among others, have been created to help implementation scientists 
understand and conceptualize key aspects of implementation processes $(21-23)$. While these frameworks have done a great deal to push forward the science of implementation, their extant differences in definitions and terminologies, use of field-specific and often technical language, and generalist scope can limit their ability to directly inform implementation efforts for (non-implementation scientist) front-line practitioners.

The goal of this study was to create an Implementation Roadmap based on the experiences of a structured partnership between research institutions, community mental health clinics/centers/agencies, and the State to assist investigators implementing novel EBIs in community settings across Michigan. Through the Implementation Roadmap, practitioners in this partnership are guided through the steps of implementation in community settings based on experiences of other projects and implementation science best practices.

\section{The Michigan Mental Health Integration Partnership}

The Michigan Mental Health Integration Partnership (MIP) is a collaboration between the Michigan Department of Health and Human Services (MDHHS) and the University of Michigan (UM) with a goal of providing administrative support to enhance services and delivery of integrated care for children and adults with behavioral health care needs that are served by Michigan's Medicaid program. MIP-associated projects link clinical experts working with MDHHS and Michigan communities to implement effective practices for depression, bipolar disorders, and other mental or behavioral disorders to enhance the quality of care and well-being of low-income citizens in Michigan. This partnership offers a structured program to expand access to novel EBIs addressing behavioral health issues and help reach populations with behavioral healthcare needs who might not receive them otherwise. As demand for Medicaid services expand, providers are increasingly strained which impacts organizations' ability to participate in the uptake of EBIs; MIP seeks to target barriers to increase EBI use in these settings (24). Since its inception in 2006, MIP has been instrumental in deploying physical and mental health integrated care in Michigan's Community Mental Health Programs. In fiscal year 2019 (FY19), 22 projects in 80 out of 83 Michigan counties were supported by MIP.

In addition to advancing evidence-based care for Michiganders with behavioral healthcare needs, MIP provides a real-time laboratory to explore implementation processes in community-based settings. A small proportion of the MIP administrative budget every year supports implementation scientists that advise investigators on their implementation efforts and inform development of tools to help MIP investigators. As MIP projects are funded one year at a time, there is relatively little time to train and orient sites to implementation practices. Additionally, most MIP investigators are not implementation scientists, but clinicians and practitioners bringing their experience and expertise to implement EBIs in community settings. They often lack either experience in community-based implementation or exposure to implementation science principles. The MIP Administrative Team opted to develop an Implementation Roadmap that laid out necessary steps and best practices that could be easily adopted by MIP investigators to inform their implementation projects. Having MIP investigators as the immediate target 
audience for the Implementation Roadmap, the team opted to use experience of recent MIP projects to inform the Roadmap.

\section{Methods}

\section{Participant Selection}

MIP projects active during FY 2019 ( $N=22)$ comprised our study population. In line with our intent to specifically define "best practices" for the Roadmap, we sought teams that were known to have had success in implementing their projects (or had seen significant EBI adoption) in one or more communitybased settings, as identified from insights shared by the Partnership Director. For all projects, we aimed to interview relevant MIP project personnel (i.e., Principal investigator [PI], project managers, key investigative/operational staff) as well as at least one key stakeholder at the community implementation site(s). Project PIs were initially approached about participating, and then were asked to identify key project staff. Upon completion of study team interviews, interviewees identified community partners that were instrumental in their implementation project for further interviews. To ensure representation of sites, study teams active at more than one site were asked to identify both "early adopters" (25) (or community partners that had few issues implementing the EBI) as well as partners that experienced more barriers to implementation. Our team then contacted these partners for interviews. We continued conducting interviews with new MIP teams until thematic saturation of research questions was reached, both within and across MIP project teams. As MIP is designed to inform statewide policy related to behavioral health, we also reached out to key MDHHS personnel for interviews to represent the state policy lens, especially on matters related to statewide diffusion and long-term sustainability of new EBIs.

\section{Interview Methodology}

Interviews were semi-structured, informed by an interview guide that was developed by the MIP Administrative Team, and tailored to each group of participants based on their role in the implementation process. The interview guide was structured around three pre-specified phases of implementation, based on the updated Replicating Effective Programs (REP) framework, which we anticipated would form the basis of the Implementation Roadmap: pre-implementation, implementation, and sustainability (26). Interviews were generally 60 minutes in length, and were conducted in-person or over the phone when requested. All interviews obtained verbal consent and were digitally recorded. Interviews were generally one-on-one, but on three occasions, teams requested to have multiple project staff interviewed together. No compensation was provided for interviews. The Consolidated Criteria for Reporting Qualitative Research (CORE-Q) guided this project. This project was reviewed and considered by the University of Michigan Institutional Review Board (IRB) to be non-regulated and exempt from further IRB review.

\section{Data Analysis}

Following the interviews, recordings were verified by the interviewer and transcribed verbatim. An inductive, iterative process was used to identify emergent themes across interviews, with a focus on key 
input for the Roadmap, notably identifying the successful strategies deployed by MIP projects during implementation, implementation barriers encountered, and the lessons learned from study teams and site partners. Each interview was independently analyzed, with the interviewer generating the initial definition for all themes, and then all investigators on the MIP Administrative Team generated a consensus codebook. The codebook was reviewed after every 2-3 interviews to assess emergent categories not captured initially. NVivo 12 was used for all data management and coding.

Codes were compared across interviews and projects, and between MIP project study staff, community partners, and MDHHS staff. Common tactics, successful steps taken, and barriers or missteps identified through interviews captured by these codes were combined to identify "best practices" used in the MIP EBI implementation across MIP projects. Best practices were then grouped to align with the three phases of implementation identified from the updated REP framework: pre-implementation, implementation, and sustainability. Within each implementation phase, generalized stages were identified by grouping best practices based on tactics and experiences shared by interviewed teams; these subcategories and their content comprised the MIP Implementation Roadmap.

\section{Results}

Six MIP projects opted to participate in interviews for Roadmap development, with five of these projects recognized as having shepherded in successful community-based implementation (Table 1). $\mathrm{N}=34$ individuals representing these six projects were contacted for study interviews, and $\mathrm{N}=28$ (82\%) completed interviews. $\mathrm{N}=14(50 \%)$ were PIs, Project Managers, and study staff of six MIP study teams. All six projects provided name(s) of community-based implementation partner(s). $\mathrm{N}=11$ (39\%) interviews were completed with key stakeholders at these sites, with at least one site represented for each of the six projects. $\mathrm{N}=3(11 \%)$ interviews were conducted with MDHHS staff. $\mathrm{N}=23(82 \%)$ interviews were completed in-person, while $\mathrm{N}=5$ completed over the phone upon their requests (with three MDHHS staff and two MIP project staff) (Table 2).

\section{Informing the Roadmap}

Our analyses identified "best practices", which we then mapped onto the three phases of the REP framework and used to identify actionable steps implementers could take to help anticipate, accommodate, or alleviate implementation barriers (Figure 1, Table 3). Within each implementation phase, we present the steps identified and results from analyses explaining how they advance implementation.

\section{Pre-implementation}

Generally, interviewees recognized that preparatory work, prior to any active implementation effort, is fundamental to successful implementation efforts. However, even among the successful MIP implementation teams, both study staff and community stakeholders recognized that more time and effort could have been used to prepare. Multiple MIP study teams recommended budgeting at least 
double the amount of time originally estimated for their preparation stage. To guide the preimplementation phase, summarized in Table 4, we identified seven steps for implementers to take: (1) identifying high-priority needs; (2) engaging stakeholders; (3) selecting essential metrics; (4) assessing contextual factors; (5) clarifying core features of the $\mathrm{EBI}$; (6) refining the $\mathrm{EBl}$; and (7) adapting select features to local contexts.

\section{Identify High-priority Needs}

An early pre-implementation step for all MIP projects was the identification of needs and priorities within the communities they planned to serve. Several teams communicated that a mismatch between the needs of the community and the needs of the project could curtail implementation efforts, and encouraged aligning needs from very early on in the implementation process as a precursor to successful implementation.

\section{Engage Stakeholders}

Nearly every interviewee identified stakeholder engagement as crucial to ensuring successful EBI implementation. Especially in larger organizations, ensuring that all stakeholders were on board with the project from the beginning decreased the time spent on other pre-implementation steps. Leadership buyin was cited repeatedly, but teams also stressed the importance of bottom-up engagement. Teams stressed the importance of regular, in-person or videoconference meetings with site stakeholders, ideally with the PI present, as a way to both increase stakeholder engagement and ensure sites that study teams were invested in the EBl's success.

\section{Select Essential Metrics}

Study team members said early metric selection was important for measuring progress during the implementation process, but also helpful for engaging stakeholders during pre-implementation, and ensuring similar goals and expectations for the project across stakeholders. Project teams and investigators recognized the importance of selecting and measuring baseline values for key metrics prior to any implementation effort for informing future sustainability. For example, accurate baseline measures of provider use and fidelity of the $\mathrm{EBI}$, as well as receipt, quality of care, and outcomes among consumers who received or did not receive the $\mathrm{EBI}$ are important to determine the impact of $\mathrm{EBI}$ implementation.

\section{Assess Contextual Factors}

In line with frameworks like the CFIR, assessing the context allowed study teams to identify potential barriers or facilitators to their proposed project. Typically, the contextual factors identified by teams were those defined by the CFIR as "inner setting" characteristics (18); for example, anticipated employee time/effort available to implement the EBI, availability of protected employee time to carry out EBI implementation, current or anticipated staffing shortfalls, physical space availability, technological capacity (e.g., Electronic Health Records), and/or internal site regulatory processes. 


\section{Clarify Core Features of the EBI}

Several successful projects noted that once stakeholders were engaged and the EBI was deemed appropriate, it was important to ensure that all stakeholders understood the core features of the EBI prior to the beginning of active implementation. Study teams highlighted the importance of talking with the community stakeholders about both the scientific and practical components of the implementation effort, including outlining the project timeline and steps in the implementation process (e.g., opportunities for training, consumer follow-ups) as well as being very explicit about expectations for logistical needs, such as staffing, effort, and space. Explicitly clarifying features for all involved is important, especially when prioritizing efficiency, and necessary for completing MIP objectives in a limited time.

\section{Refine the EBI}

As is the case with most investigator-led implementation efforts, MIP teams all had an EBI in mind that they planned to implement-and indeed were funded to implement a specific EBI. Nonetheless, teams still reported that assessing the fit between their selected EBI and the identified high-priority need(s) of the site(s) was a key step. Successful projects noted that they remained open-minded about potential refinements of their intervention to ensure that implementation would be feasible in their community setting. Refining an intervention to fit the needs and setting, while ensuring preservation of essential evidence-based elements, is a key step in allowing implementation to move forward. Note that refinement of the EBI may take a couple of iterations, such as through the use of rapid-cycle testing of the EBI implementation, especially as additional barriers are discovered through assessment of contextual factors.

\section{Adapt Select Features to Local Context}

Core feature identification, EBI refinement, and contextual factor assessment all helped study teams to adapt their selected EBI to their local site's context. Nearly all studies we spoke with mentioned that some kind of adaptation had to be done, but not all sites had planned for adaptation prior to active implementation. Among several documented ways to plan for local adaptation, one that emerged from our interviews was workflow analysis. The workflow analysis process, an essential way to understand the EBI core elements, as well as to identify adaptation or menu options to local context, (e.g. via rapid cycle testing), helped the study teams to lay out a step-by-step plan detailing how their project would be carried out with their community partners. This process proved especially helpful to MIP teams implementing their EBI in multiple community settings, as it allowed them to systematically consider between-site differences, as well as concomitant differences in adaptations necessary to accommodate the variations. Another way that many teams adapted their EBI was by tailoring projects to local context based on feedback from community sites.

\section{Implementation}


Common practices to promote EBI implementation emerged across teams. From these commonalities, we identified six steps for the implementation phase (See Table 5): (1) soliciting feedback for further EBI tailoring; (2) communicating regularly; (3) maintaining engagement; (4) developing and utilizing resources; (5) supporting transitions; and (6) collecting and monitoring key metrics.

\section{Solicit Feedback and Further Tailor the EBI}

During active implementation, teams described seeking feedback from community sites and tailoring their program accordingly. Teams found that their method of implementation often needed to be tailored to particular site needs mid-course during the implementation effort, such as accommodating new barriers to implementation or adjusting to leadership changes. Although tailoring done in the preimplementation phase was important, further tailoring during active implementation, including course corrections and re-tailoring, allowed teams to readily respond to unanticipated barriers and between-site differences.

\section{Communicate Regularly}

Regular communication was important for bringing an EBI to a community setting and maintaining its implementation. Best regular communication practices were not limited to content, but also included thoughtfulness and efficient communication. Engaging in regular communication while being careful not to overburden partners is a fine line for teams to walk. Steps that reduce the communication burden on community sites, such as minimizing the number of reporting documents required or giving ample notice when reports are due, enhances effectiveness of communication.

\section{Maintain Engagement}

Maintaining provider engagement with the $\mathrm{EBI}$ was frequently noted as one of the more challenging aspects of implementation. Sending reminders was one of the frequently cited tactic, while Pl's on-site presence and face-to-face meetings were described as effective ways to maintain engagement. When onsite time was not possible, teams reported maintaining site engagement through electronic tools and online spaces to share experiences and feedback. Others reported maintaining communication between sites in similar geographic areas so that on-the-ground implementers could share their experiences with the project and engage beyond the MIP project team, further creating space for engagement.

\section{Develop and Utilize Resources}

Improving resource utilization, for example through the development and adaptation of high-quality resources related to the EBI (training manuals, websites, etc.) that community sites could easily access, was an important implementation step for many teams. Technology development around project delivery was cited by research teams as another resource that aided their implementation work. Community partners viewed technology resources as exciting and useful tools for them, especially when the introduced technology was easy to access and user friendly. 


\section{Support Transitions}

Teams noted that having supports for participating staff's transitions in the site is important step, as many of their community sites experienced high turnover both at the provider and leadership level. While reflecting on differences in implementation across sites, project teams shared working with sites with multiple participants were much more likely to allow projects to continue through transitions. Teams noted that with high turnover, and without a plan to introduce and transition the MIP project to the new staff member, the project was left behind without clear steps for onboarding new staff and study teams felt like they needed to start again at square one.

\section{Collect and Monitor Ongoing Metrics}

To both aid implementation and prepare for the sustainability, collecting and monitoring identified key metrics was helpful. This includes data on EBI use and quality, consumer outcomes, implementation fidelity, and provider engagement. In particular, metrics for fidelity were used to ensure MIP projects could be applied with fidelity in their chosen setting, which in turn was a key to overcome recognized implementation barriers and to support successful adoption of the EBI. Teams noted that, throughout the full implementation effort, they maintained various tools to ensure the fidelity of their implementation strategies, including developing a fidelity tool, selecting specific components to monitor, using selfratings, and using observed ratings.

\section{Sustainability}

To sustain MIP projects beyond initial implementation efforts, MIP teams benefited from having a sustainability plan in place to guide them throughout the implementation process. While plans varied by teams based on funding sources, long-term goals, and other team-specific factors, many teams took similar steps to move their projects to a sustainable model. For the sustainability phase of the Roadmap, we identified four steps for implementers to take as summarized in Table 6: (1) analyzing and using collected data, (2) determining costs and establishing a return on investment, (3) establishing a business model, and (4) planning to transition ownership to stakeholders.

\section{Analyze and Use Collected Data}

The data collected by MIP research teams throughout their EBI implementation were the most useful tools they had to advocate for resources to help promote the sustainability of their projects. Teams utilized data to show stakeholders the impact of their programs. Analyzing collected data was also a benefit for the teams themselves by highlighting successes and positive outcomes. Sharing and presenting results from data collected throughout the implementation process helped the project teams to advocate for the sustainability of MIP projects while also allowing teams themselves to reflect on, show progress, and continue improving the implementation of their EBI.

\section{Determine Costs and Establish Return-On-Investment}


Replicating, scaling and maintaining EBI implementation requires a determination of costs. Questions around costs are often one of the first factors that site leadership (or policy makers) consider when evaluating projects' impacts $(27,28)$. This includes not just the costs to support the EBI directly, but also staffing time for practitioners delivering the EBI and program oversight, technological costs, physical resources, and costs for documenting any key metrics or other EBI information. Exact inputs will vary across programs, and implementers should take time to consider these inputs when determining their program costs.

An important step in moving towards sustainability is establishing the return-on-investment for community-implemented projects. The ability to demonstrate to stakeholders that the resources necessary to start and maintain the EBI can pay dividends, for example, improved clinical outcomes, increased community throughput, or decreased employee turnover or burnout, improves the potential for scaling EBI implementation efforts.

\section{Establish Business Model}

Implementation projects' ultimate goal is to have a model where projects are not tied to grant funding and can sustain independently of short-term mechanisms (e.g., grant funding). For many MIP projects, the biggest barrier to sustainability was a lack of billing codes for the practice. MIP's partnership with MDHHS provided access to key policymakers that could help implementers pursue changes to billing codes (29); however, metrics related to cost and effectiveness were necessary to motivate policy change. Establishing a business model for the EBI that includes information on the costs, return-on-investment, as well as the relationships needed to move a sustainable model forward furthers implementation efforts by showing how projects can exist outside of the MIP/Medicaid funding model. In many cases, however, the knowledge necessary to develop a strong business model is not native to the implementing team, so frontline implementers may want to consider contracting this expertise.

\section{Plan to Transition Ownership to Stakeholders}

One of the last steps in sustaining EBI implementation is transitioning ownership from the MIP research teams to the stakeholder(s) at the community organization where the EBI has been implemented. This includes preparing for ownership transition to stakeholders by developing plans with implementers at their site, identifying who would review outcomes and measures, who would be able to re-correct the project if necessary, and who would house and disseminate training tools when workforce turnover occurs. Pulling from the work done in other stages outlined in the Implementation Roadmap, research partners, community sites, and other stakeholders can work together to ensure a viable plan for ownership transition is in place in order to support the future of these projects.

Stakeholders at MDHHS are also invested in the sustainability of these programs beyond the Medicaid matched funding mechanism. Partners at MDHHS have said that they want projects that have a sustainable funding plan and utilizing these relationships to transition financial ownership is a key step in garnering longer-term sustainability for successful projects. For example, if pursuing billing codes for 
specific services, teams need to be linking up with the correct people from the beginning to pursue this funding route. MIP is uniquely situated in that these projects can connect with key personnel in the government of the State of Michigan because of the partnership with MDHHS. This mechanism may make it easier for options like approving to fund (or pay for) certain billing codes to be pursued through the relationships this partnership affords (29). Additionally, the State of Michigan has already demonstrated their support through its decision to fund these programs and may be more able to help sustain the delivery of these programs through alternative funding mechanisms.

\section{Discussion}

Sustainable implementation with fidelity is a difficult process (30); while knowledge of implementation science does not necessarily make implementation easier, it can help frontline implementers demystify the process by helping prepare for potential barriers, understanding strategies for addressing barriers, and structuring long-term thinking $(5,6,31,32)$. As with many other academic-driven implementation efforts, MIP investigators and study teams are often leading experts in EBI development and testing, but have less expertise in transitioning their EBI to community-based practice and ownership.

The MIP Implementation Roadmap was primarily developed to enhance the practice of implementation, based in part on the extensive work by implementation researchers to develop comprehensive frameworks on the implementation process (33). The Roadmap also builds upon the emerging implementation strategy literature, which is primarily focused on the "how to" of implementation science in which specific tools or methods are specified that help improve EBI uptake. Notably, the VA's QUERI Implementation Roadmap was developed to de-mystify implementation science and encourage active partnerships between implementers health care leaders, and practitioners (14). The MIP roadmap intends to accomplish similar goals with a specific focus on the challenges facing non-implementation scientists, both researchers and community partners, working in community-based settings. While the MIP Implementation Roadmap is not a one-size-fits-all solution to implementation, it can help investigators navigate the steps common to implementation efforts and anticipate potential barriers, pain points, or missteps. For MIP implementation projects, which are often funded for a single year, efficient use of time is critical for meeting implementation goals. Our creation of the MIP Implementation Roadmap was motivated by a desire to assist new investigators with the design and evaluation of their communitybased implementation efforts.

Although the MIP Implementation Roadmap is presented as a one-way progression, it is not necessarily meant to be followed linearly. Projects may need to address stages at different times and frequently steps or stages, such as rapid cycle testing of a tailored EBI, may need to be revisited. Keeping that in mind, the MIP Implementation Roadmap may be more easily seen as a tool to guide implementers through iterative cycles of planning, experimenting, reflecting, and refining until the goals of their projects are reached. 
In interviews with all MIP project teams and community partners, participants were asked to identify actions they took that were most helpful to their EBI implementation to help define the best practices they utilized to achieve successful implementation of their EBI in their community setting. Oftentimes, this conversation quickly turned to lessons learned from unexpected barriers teams encountered and the methods they deployed to overcome these challenges. Although each team identified unique problems and solutions, there were similarities to the types of challenges teams encountered. By incorporating these shared experiences into the stages outlined in the Implementation Roadmap, future MIP projects may be able to proactively avoid common barriers and be better equipped to address the challenges that are commonly faced with implementing these types of EBls in community settings.

When interviewing both research teams and community partners, implementers did not always think of the planning and preparation they were doing as part of the implementation process. The Roadmap's elucidation of these steps as comprising the key pre-implementation phase is intended to encourage implementers to tie these planning efforts more explicitly to the goals of the implementation process. Indeed, interviews identified the largest number of barriers and best practices pertaining to the preimplementation phase. Although the steps taken in this phase were not necessarily considered "implementation" by teams, interviews revealed they were important to projects' successes and often required the most time and energy from project stakeholders. By specifically defining the preimplementation phase on the Roadmap, the hope is that teams will have guidance on ways to set themselves up for success, and view these steps as integral to the implementation effort as a whole.

Although conversations around pre-implementation and implementation phases were focused on actions MIP projects had completed or were currently completing, conversations around sustainability were often hypothetical, as most MIP projects had not yet reached this stage at the time of their interviews. However, by talking with teams and investigators about what they planned to do or wish they had done sooner, we were able to understand the key challenges facing MIP project sustainability and identify steps or considerations for teams even as they begin implementation efforts.

The main threat to sustainability of most implementation projects is securing funding beyond an initial grant or funding allocation. As discussed in the sustainability phase, one of the main steps identified by MIP teams for securing a funding source beyond the year of funding guaranteed by MIP was working to develop sustainable revenue streams (e.g., turn on billing codes) for their particular project once positive patient outcomes had been demonstrated. Once established, this would allow practitioners at the community sites where projects are being implemented to bill insurance for the services that they are providing, thus eliminating the need for a grant funding mechanism. Although demonstrated as a viable option forward, many research teams noted in their interviews that they were struggling to accomplish this.

As noted in the introduction, roadmaps in general are tools that can be used for structuring process flows. We developed this Implementation Roadmap to help guide projects through early-stage implementation efforts and beyond, regardless of a practitioner's experience in implementation. When used from a 
project's inception, our Implementation Roadmap can help frontline implementers systematically anticipate and address barriers to the implementation of their EBI and ensure the collection of key metrics that can aid successful implementation and sustainability; our Implementation Roadmap provides scaffolding for larger scale, sustainable implementation efforts for EBIs.

The MIP mechanism specifically affords a more direct opportunity for EBI developers and experts to implement their effective practices in communities. However, states need a guide to ensure that programs supported through Medicaid Match are sustained at both the clinical and policy levels. This Implementation Roadmap can help in this endeavor by informing a process by which implementation occurs in community practices traditionally affiliated with large research programs. Although the MIP Implementation Roadmap was purposefully designed for intended use by future MIP programs, many of the steps and stages of implementation highlighted can be generalized to community-based implementation projects outside of the MIP partnership.

\section{Limitations}

There were limitations faced in the creation of this Roadmap. First, this was a relatively small qualitative study involving interviews with stakeholders from six MIP community-based implementation projects for a single fiscal year. Including a larger number of MIP projects (or implementation efforts outside of MIP) may have led to identification of additional or alternative themes and/or best practices. Despite this limited population, the themes and practices identified by this diverse group of stakeholders align with much knowledge in this field. Second, it is difficult to balance the specificity of individual experiences with the generalizability of recommendations designed to apply across multiple contexts. As projects focused on EBI implementation, many did not have the resources or time to develop common tools or methods such as workflow or process maps or cost estimation that could be useful in operationalizing key Roadmap components elsewhere. In the process of creating accomplishable stages to aid in the implementation process more globally, the specificity and utility of some recommendations may have been diminished or not fully captured by the Roadmap. Third, interviews and analysis were performed by only one author. This limitation could have introduced bias into the transcript coding process.

\section{Future Directions}

The MIP Implementation Roadmap is designed to be a dynamic guide that may evolve based on the needs and experiences of future MIP projects and/or changes in community-based implementation environments. The MIP Administrative Team next plans to solicit feedback from MIP investigators, sites, and MDHHS stakeholders involved with MIP, including projects that informed the initial Roadmap and new projects. The team also plans to deploy the Roadmap with future MIP investigators and evaluate its added value to implementation efforts, ability to address implementation barriers, and utility for practitioners. Additionally, although the MIP Implementation Roadmap was designed with MIP projects in mind, MIP is actively looking for opportunities to adapt it to new clinical or organizational settings. 


\section{Conclusion}

The MIP Implementation Roadmap can guide MIP investigators, teams, and partners through preimplementation, implementation, and sustainability phases of early efforts to implement evidence-based EBIs, improving the effectiveness of current implementation efforts and providing scaffolding for larger scale, sustainable implementation. Although specifically designed from MIP projects' experiences and for MIP project teams, components of this Implementation Roadmap can be applied to implementation of a wide variety of evidence-based practices, implementation efforts, or programs. This roadmap provides actionable guidance beyond traditional research-to-practice frameworks relevant to the implementation of a wide variety of EBIs, including those outside of the MIP partnership. By focusing on practical and user-friendly steps, this tool can help demystify implementation for frontline clinicians, researchers, partner leadership, and community stakeholders alike for a range of community-based EBI efforts. Using the steps outlined in the Implementation Roadmap to develop implementation plans will help establish and aid in the scale up of behavioral health programs in community settings regardless of practitioners' familiarity with implementation practice.

\section{Abbreviations}

\begin{tabular}{ll} 
CFIR & Consolidated Framework for Implementation Research \\
\hline$E B I(s)$ & Evidence-based Intervention(s) \\
\hline$E P I S$ & Exploration, Preparation, Implementation, Sustainment \\
\hline$F Y$ & Fiscal Year \\
\hline$I R B$ & Institutional Review Board \\
\hline$M D H H S$ & Michigan Department of Health and Human Services \\
\hline MIP & Michigan Mental Health Integration Partnership \\
\hline$P I$ & Principal Investigator \\
\hline QUERI & Quality Enhancement Research Initiative \\
\hline$R E-A I M$ & Reach, Effectiveness, Adoption, Implementation, and Maintenance \\
\hline$R E P$ & Replicating Effective Programs \\
\hline$U M$ & University of Michigan
\end{tabular}

\section{Declarations}

\section{Ethics approval and consent to participate:}

This project was reviewed and considered by the University of Michigan Institutional Review Board (IRB) to be non-regulated and exempt from further IRB review. 


\section{Consent for Publication:}

Not applicable

\section{Availability of data and material:}

Data sharing is not applicable to this article as no datasets were generated or analysed during the current study.

\section{Competing interests:}

The authors declare that they have no competing interests.

\section{Funding:}

This project was supported by funds from the Center of Medicare and Medicaid Services through the Michigan Department of Health and Human Services.

\section{Authors' contributions:}

LD, AK, and SS conceived and designed the MIP Implementation Roadmap project. AR, LD, CL, GD, AK and SS provided input on the interview guide and recruitment process. AR collected the qualitative data, transcribed interviews, and carried out the analysis. LD, CL, SY, AK, and SS reviewed and contributed to interpretation of findings. AR wrote the manuscript. CL, SC, GD, AK, and SS provided input on early drafts of the Implementation Roadmap and manuscript, including critical review. All authors reviewed and revised the manuscript. All authors gave their approval of the submitted version of the manuscript.

\section{Acknowledgements:}

Not applicable

Funding Declaration: This project was supported by funds from the Center of Medicare and Medicaid Services through the Michigan Department of Health and Human Services.

Declaration of Conflicting Interests: The Authors declare that there is no conflict of interest.

\section{References}

1. Kitson A, Harvey G, McCormack B. Enabling the implementation of evidence based practice: A conceptual framework. Qual Saf Heal Care [Internet]. 1998 Sep 1 [cited 2020 Jul 27];7(3):149-58. Available from: http://qualitysafety.bmj.com/

2. Katzelnick DJ, Williams MD. Large-Scale Dissemination of Collaborative Care and Implications for Psychiatry. Psychiatr Serv [Internet]. 2015 Sep 1 [cited 2020 Nov 13];66(9):904-6. Available from: http://psychiatryonline.org/doi/10.1176/appi.ps.201400529 
3. Green LW, Ottoson JM, García C, Hiatt RA. Diffusion Theory and Knowledge Dissemination, Utilization, and Integration in Public Health. Annu Rev Public Health [Internet]. 2009 Apr [cited 2020 Jul 27];30(1):151-74. Available from: https://pubmed.ncbi.nlm.nih.gov/19705558/

4. Proctor EK, Landsverk J, Aarons G, Chambers D, Glisson C, Mittman B. Implementation research in mental health services: An emerging science with conceptual, methodological, and training challenges. Adm Policy Ment Heal Ment Heal Serv Res. 2009 Jan;36(1):24-34.

5. McHugo GJ, Drake RE, Whitley R, Bond GR, Campbell K, Rapp CA, et al. Fidelity outcomes in the national implementing evidence-based practices project. Psychiatr Serv. 2007;58(10):1279-84.

6. Bauer MS, Kirchner JA. Implementation science: What is it and why should I care? [Internet]. Vol. 283, Psychiatry Research. Elsevier Ireland Ltd; 2020 [cited 2020 Jul 27]. Available from: https://pubmed.ncbi.nlm.nih.gov/31036287/

7. Phaal R, Farrukh C, Mitchell R, Probert D. Starting-Up Roadmapping Fast. Res Manag [Internet]. 2003 [cited 2020 Jul 27];46(2):52-9. Available from: https://www.tandfonline.com/action/journallnformation?journalCode=urtm20

8. de Laat, B., Mckibbin S. The Effectiveness of Technology Road Mapping: Building a Strategic Vision. Hague Minist Econ Aff. 2003;

9. Gholamzadeh Chofreh A, Ariani Goni F, Mohamed Shaharoun A, Ismail S. Review on Enterprise Resource Planning Implementation Roadmap: Project Management Perspective. Sains Humanika [Internet]. 2014 Sep 9 [cited 2020 Jul 27];2(2). Available from: www.sainshumanika.utm.my

10. Gholamzadeh Chofreh A, Editors G, Sabev Varbanov P, Liew P-Y, Yong J-Y, Jaromír Klemeš J, et al. A Master Plan for the Implementation of Sustainable Enterprise Resource Planning Systems (Part II): Development of a Roadmap (Summary) A master plan for the implementation of sustainable enterprise resource planning systems View project A Master Plan for the Implementation of Sustainable Enterprise Resource Planning Systems (Part II): Development of a Roadmap. In: CHEMICAL ENGINEERING TRANSACTIONS [Internet]. 2016 [cited 2020 Jul 27]. Available from: www.aidic.it/cet

11. Phaal R. Technology roadmapping - A planning framework for evolution and revolution. Technol Forecast Soc Change. 2004 Jan 1;71(1-2):5-26.

12. Metz A, Bartley L. Active Implementation Frameworks for Program Success. 2012.

13. Olds DL. The nurse-family partnership: An evidence-based preventive intervention. Infant Ment Health $J$ [Internet]. 2006 Jan 1 [cited 2020 Nov 13];27(1):5-25. Available from:

https://onlinelibrary.wiley.com/doi/full/10.1002/imhj.20077

14. Kilbourne AM, Goodrich DE, Miake-Lye I, Braganza MZ, Bowersox NW. Quality Enhancement Research Initiative Implementation Roadmap: Toward Sustainability of Evidence-based Practices in a Learning Health System. Med Care [Internet]. 2019 Oct 1 [cited 2020 Jul 27];57(10 Suppl 3):S28693. Available from: /pmc/articles/PMC6750196/?report=abstract

15. Belin TR, Jones A, Tang L, Chung B, Stockdale SE, Jones F, et al. Maintaining internal validity in community partnered participatory research: Experience from the community partners in care study. 
Ethn Dis [Internet]. 2018 Sep 1 [cited 2020 Jul 27];28(Suppl 2):357-64. Available from: /pmc/articles/PMC6128339/?report=abstract

16. Stewart RE, Beidas RS, Mandell DS. Stop Calling Them Laggards: Strategies for Encouraging Nonadopters to Incorporate Evidence-Based Practices. Psychiatr Serv [Internet]. 2019 Oct 1 [cited 2020 Jul 27];70(10):958-60. Available from:

https://psychiatryonline.org/doi/10.1176/appi.ps.201900031

17. Wells KB, Jones L, Chung B, Dixon EL, Tang L, Gilmore J, et al. Community-partnered clusterrandomized comparative effectiveness trial of community engagement and planning or resources for services to address depression disparities. J Gen Intern Med [Internet]. 2013 May 7 [cited 2020 Jul 27];28(10):1268-78. Available from: http://www.rand.org/health/projects/pic.html

18. Damschroder LJ, Aron DC, Keith RE, Kirsh SR, Alexander JA, Lowery JC. Fostering implementation of health services research findings into practice: A consolidated framework for advancing implementation science. Implement Sci [Internet]. 2009 Dec 7 [cited 2020 Jul 27];4(1):50. Available from: http://implementationscience.biomedcentral.com/articles/10.1186/1748-5908-4-50

19. Aarons GA, Hurlburt M, Horwitz SMC. Advancing a conceptual model of evidence-based practice implementation in public service sectors. Adm Policy Ment Heal Ment Heal Serv Res [Internet]. 2011 Jan 14 [cited 2020 Jul 27];38(1):4-23. Available from: https://link.springer.com/article/10.1007/s10488-010-0327-7

20. Glasgow RE, Vogt TM, Boles SM. Evaluating the public health impact of health promotion interventions: The RE-AIM framework [Internet]. Vol. 89, American Journal of Public Health. American Public Health Association Inc.; 1999 [cited 2020 Jul 27]. p. 1322-7. Available from: www.ori.

21. Atkins L, Francis J, Islam R, O'Connor D, Patey A, Ivers N, et al. A guide to using the Theoretical Domains Framework of behaviour change to investigate implementation problems. Implement Sci [Internet]. 2017 Jun 21 [cited 2020 Jul 27];12(1):1-18. Available from:

https://link.springer.com/articles/10.1186/s13012-017-0605-9

22. Bunger AC, Powell BJ, Robertson HA, MacDowell H, Birken SA, Shea C. Tracking implementation strategies: A description of a practical approach and early findings. Heal Res Policy Syst [Internet]. 2017 Feb 23 [cited 2020 Jul 27];15(1):1-12. Available from: https://link.springer.com/articles/10.1186/s12961-017-0175-y

23. Damschroder LJ. Clarity out of chaos: Use of theory in implementation research. Psychiatry Res. 2020 Jan 1;283:112461.

24. Sparer MS. Medicaid at 50: Remarkable growth fueled by unexpected politics. Health Aff. 2015 Aug 2;34(7):1084-91.

25. Rogers EM. Diffusion of Innovations. Fourth. New York: The Free Press; 1995.

26. Kilbourne AM, Neumann MS, Pincus HA, Bauer MS, Stall R. Implementing evidence-based interventions in health care: Application of the replicating effective programs framework. Implement Sci [Internet]. 2007 Dec 9 [cited 2020 Jul 27];2(1):1-10. Available from: https://link.springer.com/articles/10.1186/1748-5908-2-42 
27. Eisman AB, Kilbourne AM, Dopp AR, Saldana L, Eisenberg D. Economic evaluation in implementation science: Making the business case for implementation strategies. Psychiatry Res. 2020 Jan 1;283:112433.

28. Saldana L, Chamberlain P, Bradford WD, Campbell M, Landsverk J. The cost of implementing new strategies (COINS): A method for mapping implementation resources using the stages of implementation completion. Child Youth Serv Rev. 2014 Apr 1;39:177-82.

29. O'donnell AN, Williams M, Kilbourne AM. Overcoming Roadblocks: Current and Emerging Reimbursement Strategies for Integrated Mental Health Services in Primary Care. 2013;

30. Breitenstein SM, Gross D, Garvey CA, Hill C, Fogg L, Resnick B. Implementation fidelity in communitybased interventions. Res Nurs Heal [Internet]. 2010 Apr 1 [cited 2020 Nov 13];33(2):164-73. Available from: https://onlinelibrary.wiley.com/doi/full/10.1002/nur.20373

31. Glasgow RE, Chambers D. Developing Robust, Sustainable, Implementation Systems Using Rigorous, Rapid and Relevant Science. Clin Transl Sci [Internet]. 2012 Feb 1 [cited 2020 Nov 13];5(1):48-55. Available from: https://ascpt.onlinelibrary.wiley.com/doi/full/10.1111/j.1752-8062.2011.00383.x

32. Bauer MS, Damschroder L, Hagedorn H, Smith J, Kilbourne AM. An introduction to implementation science for the non-specialist. BMC Psychol [Internet]. 2015 Sep 16 [cited 2020 Nov 13];3(1):1-12. Available from: https://link.springer.com/articles/10.1186/s40359-015-0089-9

33. Moullin JC, Dickson KS, Stadnick NA, Rabin B, Aarons GA. Systematic review of the Exploration, Preparation, Implementation, Sustainment (EPIS) framework [Internet]. Vol. 14, Implementation Science. BioMed Central Ltd.; 2019 [cited 2020 Jul 27]. p. 1-16. Available from: https://link.springer.com/articles/10.1186/s13012-018-0842-6

\section{Tables}

Table 1 Project (EBIs) Informing MIP Implementation Roadmap Development 


\begin{tabular}{|c|c|c|c|c|}
\hline Project Goals & $\begin{array}{l}\text { Professionals } \\
\text { Delivering EBI }\end{array}$ & $\begin{array}{l}\text { Primary } \\
\text { EBI Target } \\
\text { Population }\end{array}$ & $\begin{array}{l}\text { Service } \\
\text { Delivery Sites }\end{array}$ & $\begin{array}{l}\text { Data } \\
\text { Providers } \\
\text { Informing MIP } \\
\text { Roadmap }\end{array}$ \\
\hline $\begin{array}{l}\text { Implement and evaluate a 3- } \\
\text { tiered model of behavioral health } \\
\text { programming that will provide } \\
\text { evidence-based mental health } \\
\text { prevention-to-intervention } \\
\text { services to schools }\end{array}$ & $\begin{array}{l}\text { Trained } \\
\text { School } \\
\text { Professionals }\end{array}$ & Youth & School & $\begin{array}{l}\text { PI, Project } \\
\text { Manager, } \\
\text { Community } \\
\text { Partners } \\
\text { (School } \\
\text { Professionals) }\end{array}$ \\
\hline $\begin{array}{l}\text { Provide services including just-in- } \\
\text { time phone consultation to } \\
\text { primary care providers and tele- } \\
\text { psychiatry consultation to youth; } \\
\text { Expand the roles of embedded } \\
\text { Behavioral Health Consultants to } \\
\text { increase access to mental health } \\
\text { treatment for underserved youth } \\
\text { \& high risk perinatal women }\end{array}$ & $\begin{array}{l}\text { Primary Care } \\
\text { Providers }\end{array}$ & Youth & Hospital/Clinic & $\begin{array}{l}\text { PI, Project } \\
\text { Manager, } \\
\text { Project Staff, } \\
\text { Community } \\
\text { Partners } \\
\text { (Behavioral } \\
\text { Health } \\
\text { Consultants) }\end{array}$ \\
\hline $\begin{array}{l}\text { Develop and implement a } \\
\text { program for high-risk fathers to } \\
\text { support family engagement } \\
\text { through parenting and family } \\
\text { support interventions, activities } \\
\text { for school and work re-- } \\
\text { integration, and family service } \\
\text { connections }\end{array}$ & $\begin{array}{l}\text { Family } \\
\text { Service } \\
\text { Employees }\end{array}$ & Adult & $\begin{array}{l}\text { Family Service } \\
\text { Center }\end{array}$ & $\begin{array}{l}\text { PI, Project } \\
\text { Manager }\end{array}$ \\
\hline $\begin{array}{l}\text { Develop standard protocols and } \\
\text { reporting mechanisms for } \\
\text { medical and mental health care } \\
\text { use and quality of care among } \\
\text { CMH clients from the county } \\
\text { using real-time and population- } \\
\text { based data to build a care bridge }\end{array}$ & $\begin{array}{l}\text { County } \\
\text { Agency } \\
\text { Providers } \\
\text { (multiple } \\
\text { roles) }\end{array}$ & Adult & $\begin{array}{l}\text { Community } \\
\text { Mental Health } \\
\text { Agency }\end{array}$ & $\begin{array}{l}\text { PI, Community } \\
\text { Partner } \\
\text { (Deputy } \\
\text { Director) }\end{array}$ \\
\hline $\begin{array}{l}\text { Develop and implement a } \\
\text { program delivered through } \\
\text { obstetric clinics for high-risk } \\
\text { women who are preconception, } \\
\text { pregnant or between pregnancies } \\
\text { to promote positive maternal- } \\
\text { fetal/infant outcomes }\end{array}$ & $\begin{array}{l}\text { Obstetric } \\
\text { Providers }\end{array}$ & Adult & Hospital/Clinic & $\begin{array}{l}\text { PI, Project } \\
\text { Manager, } \\
\text { Community } \\
\text { Partner } \\
\text { (Doctor, } \\
\text { Clinical } \\
\text { Coordinator) }\end{array}$ \\
\hline $\begin{array}{l}\text { Build and evaluate a } \\
\text { Collaborative Care }\end{array}$ & $\begin{array}{l}\text { Community } \\
\text { Health Care }\end{array}$ & Adult & $\begin{array}{l}\text { Community } \\
\text { Health Center }\end{array}$ & $\begin{array}{l}\text { PI, Project } \\
\text { Manager, }\end{array}$ \\
\hline
\end{tabular}


Implementation and Support

Team that will train and provide technical assistance to

Community Health Centers to

implement the collaborative care

model
Providers

Project Staff, Community

Partners

(Clinical

Director, QI

Coordinator)

Table 2 Stakeholders Interviewed to Inform MIP Implementation Roadmap Development

\begin{tabular}{|llll|}
\hline Definition & Project teams & Community partners & MDHHS staff \\
$\begin{array}{l}\text { Project team interviews } \\
\text { included Pls, Project } \\
\text { Managers, and other } \\
\text { staff key to the } \\
\text { implementation } \\
\text { process }\end{array}$ & $\begin{array}{l}\text { Community Partners were key } \\
\text { personnel at the implementation } \\
\text { site projects were implementing } \\
\text { their projects at and assisted in } \\
\text { implementation efforts }\end{array}$ & $\begin{array}{l}\text { Staff members at } \\
\text { MDHHS interviewed } \\
\text { are part of the MIP }\end{array}$ & $\begin{array}{l}\text { Partnership and } \\
\text { review/approve MIP } \\
\text { projects }\end{array}$ \\
\hline $\begin{array}{l}\text { \# of } \\
\text { interviews } \\
(\mathbf{N}=28)\end{array}$ & 14 & 11 & 3 \\
\hline $\begin{array}{l}\text { Project } \\
\text { coverage } \\
(\mathbf{N}=22)^{a}\end{array}$ & 6 & 6 & All Projects \\
\hline
\end{tabular}

Note. ${ }^{a}$ not all projects contacted for interviews

Table 3 Implementation Roadmap Components 


Implementation
phase $\begin{aligned} & \text { Implementation } \\ & \text { roadmap } \\ & \text { component }\end{aligned}$

\section{Pre-} implementation
Identify High

Priority Needs

Disconnect between needs of community and needs of research project can impact implementation success. Align needs from the start. Performing a formal needs assessment on-site can ensure that stakeholder-communicated needs were consistent with observed "on the ground" needs and that the $\mathrm{EBI}$ aligned with the specific, high-priority needs of the community.

Engage Stakeholders

Bring together diverse representatives from all constituents and stakeholders from the beginning. Regular meetings with frontline "day-to-day" practitioner and implementers from the start to ensure ongoing investment. Identification of a project champion who can advocate for EBI use when the implementation project team was not physically present.

Select Essential Metrics

Take time to develop organization/reporting systems from the start. Plan for their utility throughout the implementation and sustainability phases of a project. Sample metrics to consider collecting data on and monitoring include number of providers trained, number of consumers receiving EBI, counties served, etc.

Assess Contextual Factors
On-site staff do not necessarily know what leadership is agreeing to, so webinars/calls/meetings with these staff members can help minimize miscommunication and confusion from the start. Time-intensive tasks often fall outside of the immediate research teams' control, and the research teams, community partners, and MDHHS all operate under different time constraints; assessing and budgeting for these differences in timelines can lead to better EBI implementation. Collaborate with partners to identify/plan for all contextual factors that could impact EBI implementation and establish norms for revisiting these plans if/when other factors arise.

Clarify Core Features of the $\mathrm{EBI}$

Talk about practical components, i.e. explicitly what the project will look like, space needs, staffing needs, technology availability, and roll out plan, initially. Walk through a process mapping exercise with partners for EBI implementation before implementation begins.

Refine the EBI

Do a needs assessment. Spend time at sites to see the needs in the context of the community setting, if viable. Remain open to refinements throughout the pre-implementation process and encourage community partner participation and feedback in this step.

Adapt Select Features To Local Context
Send team members physically to sites to understand the local context. Workflows vary by clinics so allow for workflows to be tailored to local circumstances. 


\section{Implementation Implementation Example actions phase \\ roadmap \\ component}

Implementation Solicit

feedback and

further tailor

EBI

Communicate regularly
Solicit feedback frequently and adapt as needed via emails, polls, phone calls or visits. Gather feedback from different levels of the organization.

Maintain face to face meetings when possible, following up on relationship building from pre-implementation. Maintain site engagement through electronic tools and online spaces to share experiences and feedback both between community sites and research teams as well as among community sites. Share expertise and findings when possible and appropriate.

Maintain engagement

Timing between recruitment for and initiation of an EBI can be long and lead to engagement struggles. Once started, regional support groups are good opportunities for growing teams to report to each other and continue conversations as teams spread across the state.

Develop and utilize Invest in high quality, useful material. Monitor the needs of resources community partners and use the implementation process to develop needed resources that can be used long-term by community sites. Consider developing technological-based tools and resources that can be tailored to sites.

\section{Support} transitions

Leadership transitions are unpredictable and hard to prepare for, so work with partners early when a leadership change is announced. Community sites can experience higher staff turnover, so develop a plan to maintain implementation should staff changes occur.

Collect and monitor key metrics
Be upfront that documentation and reporting takes time. Reporting requirements can get burdensome, so be upfront about the process for data collection and monitoring as it begins. Plan for opportunities to share collected data and findings with community partners throughout the implementation process.

Sustainability
Analyze and use collected data

Determine costs and establish a return on investment
Showing evidence of efficiency and effectiveness and fidelity allows projects to expand. Analyze collected metrics and inform stakeholders of project impacts.

Compensate providers/implementers for their time whenever possible. Consider their time as part of your costs. Consider outcomes impacted by EBI implementation beyond primary health outcomes; include outcomes as part of projects' return on investment. 
Establish a $\quad$ Ability to fund staff working on a project beyond the year(s) of business model funding is problematic for some sites. Consider solutions before funding is removed. Utilize partnerships with MDHHS to carry out conversations with policymakers/funders on longterm funding mechanisms.

Plan to transition Think about the policy implications of the work being ownership to done/carried out and how that can be used to influence stakeholders sustainability from a policy perspective. This can often be incentivizing for sites.

Table 4 Pre-Implementation Illustrative Quotes 


\section{Pre- Supporting quotations from interviews
implementation \\ phases}

Identify high- "Our project was definitely not a solution looking for a problem, it was the other priority needs way around." [Project Staff Member]

\section{Engage stakeholders}

"[O]ne thing I learned earlier on was to really engage all the right people at the table. We were told, 'These are the right people to talk to. This doctor, that person...' and it turned out while they were important people, they were not the right people." [PI]

"Engaging leadership will get you in the door, but engaging opinion leaders will keep you in the house." [PI]

"It's building the relationships, making sure that everyone is involved from the get go. Really valuing everyone's contributions but also always thinking about, I know what I need out of this, but that might be different than another one of the stakeholders needs to get out of this and how do we make sure that we're addressing all of those things." [PI]

Select essential metrics
"To build rapport and make our program a reality we needed to go in person, bring food, and have those meetings." [Project Manager]

"Since our project is still kind of in the beginning stages, we are being thoughtful as far as data collection. We do have a statistician who specializes in cost effectiveness because it's not something that in general we have, those data analyses we'd like to do is kind of its own thing. So just even thinking ahead of time, if we're gonna want to show that, what do we need data wise to be able to do that." [PI]

"You don't want to just do something for the research so we actually involved [community sites] in choosing measures when we did trainings for all of their clinicians." [Project Staff Member]

"Our team started by thinking through every aspect of how this might work and what we need to do to figure this out. Do we have psychiatrists that are available? Are we gonna cover their effort? What does their day look like? How are they gonna answer the phone? How's the call gonna come to them? How's the information gonna come to them? What information do we need to gather? We just started digging into the details for every component." [Project Manager]

Clarify core features of the EBI
While initial conversations about the project went "really, really well, six months down the road when we're implementing we found out that those conversations didn't trickle down to the right people....and it's almost like restarting and reselling all of the reasons that we're doing this." [Project Staff Member]

Refine the EBI
"I think keeping in mind what the need of the community is rather than the need of the program, that's really critical... if you build a program that's responsive to that need, it's gonna be adopted and utilized widely. If you build a program that fits 
your need as a researcher, but doesn't fit a need in that community, it's not gonna be used." [PI]

"Programs need to be low barrier... and very user friendly for those delivering [the EBI] in order for our community sites to use new practices." [Project Manager]

Adapt select features to

"I really struggled with workflow. In the beginning there were a lot of questions of, you know 'how would we roll this out' 'what would our process be' and we couldn't really answer those questions without knowing, 'what does this entail' 'what is the workflow'." [Community Partner]

A workflow is "a couple pages that highlighted from the very beginning what to expect all the way towards the end. It helped us build a plan to know what our staff would do... and that helped a ton." [Community Partner]

"So, you know, it's really a one size does not fit all thing. So you're trying to get the program to go, but you have to tailor it a little bit to the local circumstances." [PI]

"Initially we were struggling with the planning process for bringing a new intervention to a new site, but once we were able to do a workflow analysis, we were able to understand the adjustments that needed to be made." [Community Partner]

Table 5 Implementation IIlustrative Quotes 


\section{Implementation Supporting quotations from interviews \\ phases}

Solicit

feedback and

further tailor

the EBI
To solicit regular feedback "we built in opportunities for direct feedback from participants every week in the beginning" so they could make weekly EBI adjustments in real time. This team "ended up retaining [weekly feedback opportunities] because...it ended up being a useful tool in more ways than [they] anticipated." [Project Manager]

"I definitely took note of how vastly different each of our sites are. In terms of their structure, their resources, even the providers that they have, their culture, their climate, each site is just very very different and I think our team learned very quickly and benefitted from our flexibility in approaching them uniquely." [Project Team Member]

\section{Communicate} regularly

Teams develop a varied communication strategy; for example, "we send out messages about every six months saying 'Hey, our project is still up and going. We look forward to hearing from you!' [They] send some new cards or other resources by mail or electronically. Our PI sends an update around the holidays and in the spring about the progress of the program." [Project Staff Member]

"It drives me absolutely crazy when I get some notice a few days before something is due or if it's like a big project the week before. With this program we always get adequate notice, reminders, so that's really appreciated." [Community Partner]

"That commitment to meet monthly and talk through [issues], is a big reason why this project is still going." [Community Partner]

"One way we learned to modify our transparency with site leadership was by sending out newsletters to all of the sites that have participated to give them feedback even before papers are published." [PI]

Maintain engagement

"We needed to send frequent reminders to providers about the EBI because ....at first you're the fun new thing and then they forget to keep you in the top of their tool box." [PI]

"So I always tell new people...you just have to be persistent. I call it patiently persistent. And then you have to strongly believe in what you're advocating for." [Project Manager]

Develop and utilize resources
"We [...] are developing resources and materials and adapting them to feedback. We are continuing to grow and enhance the website over time and right now a lot of sites are focusing more on implementation resources provided." [Project Team Member]

"We are using matching funds to develop a website that has been pretty critical in our training for all of our community health centers. We've basically been creating 
an online manual for both the implementation tasks for health centers as well as the trainings. We also use video webinars and things like that for people to do selfbased trainings now. We're building our technology up by the day. And at this point, if you don't have a website you're not a real thing." [Project Team Member]

"I think really creating a program that has high quality, useful materials, that will help sustain fidelity to the original seed that you wanted to disseminate. That feels really critical to me." [PI]

\section{Support} transitions
"When we have a site where there's only one person that participates, that person could get laid off or move or lose interest or not feel like they have sufficient time, and then the program can't continue." [PI]

"Sometimes conversations go really, really well and then six months down the road when you're implementing you find out that those conversations didn't trickle down to the right people or those people are gone so you're almost like retraining and reselling all of the reasons that we're doing this if you don't prepare for that." [Project Manager]
"What is better? What has better outcomes? Where are the providers more satisfied? And also what is more cost effective or if it is more expensive, is it worth the investment?" [Project Team Members]

Table 6 Sustainability Illustrative Quotes 


\section{Sustainability Supporting quotations from interviews phases}

Analyze and use collected data
"When we talked with [stakeholder], it was clear that they're invested in the sustainability of the model...they were interested in our mental health measures or parenting stress measures, and we felt the need to make these [data] clinically meaningful." [Project Team Member]

"I think the project helped open our eyes to some of the other things that maybe we didn't even realize were successes or good outcomes in the work that we were doing. Like being able to really notice increased parental reflection functioning or things that had been changing but we maybe didn't know to call it that or look for that without the study data." [Community Partner]

"The fact that we were able throughout this to develop evidence for efficacy and effectiveness and that we were able to develop a fidelity tool, a training, to sort of evaluate the training, etc., has prepared us now to really take this national." [Project Team Member]

\section{Determine costs and establish return-on- investment}

"[T]he providers that find [the EBIs] valuable use them and the providers that don't necessarily find them having as much value, don't use them in the long run." [Community Partner]

\section{Establish} business model
"For any program that wants to provide a service to a community that has no funding, without any internal or reliable funding, that's hard." [PI]

"Most programs do not want to be reliant on donor or foundation funding and match funding longer term; it's not very viable for long term sustainment. One path to sustainability is through development of a business model." [Project Manager]

Although it would be "ideal to have an established business model", the research teams participating in MIP projects often do not have individuals with a business expertise working with them directly. "The people that are building the programs, myself included, often have no background or expertise in mental health economics, or business modeling or don't have MBA's and so somebody on the team whose role was to say let me help you think about how you could generate revenue from this would be a great addition for probably many programs." [PI]

"Typically, when we're working with a community partner they'll say, 'we love this, but if we don't have a billing code to sustain it once the grant funding is gone, we can't keep doing it'." [PI]

Plan to transition ownership to stakeholders
"We are not even applying for an extension of the Medicaid Match project any more. This is it. And it doesn't mean that the project is going to end. I think our partnership [with stakeholders] is so strong that we don't necessarily need it to be a formalized Medicaid match project, because the community site is doing a lot of the things that the study team set out to do." [PI] 


\section{Figures}

Pre-Implementation

\section{Implementation}

\section{Sustainability}

\section{MIP Implementation Roadmap}

Identify high-priority needs

Engage stakeholders

Select essential metrics

Assess contextual factors

Clarify core features

Refine the EBI

Adapt select features to local context
Solicit Feedback and further tailor EBI

Communicate regularly

Maintain engagement

Develop and utilize resources

Support transitions

Collect and monitor key metrics
Analyze and use collected data

Determine cost and

establish a return on

investment

Establish a business model

Plan to transition ownership to stakeholders

\section{Figure 1}

MIP Implementation Roadmap. The MIP Implementation Roadmap. Each Phase of the Implementation Roadmap, Pre-implementation, Implementation, and Sustainability, contains generalized stages to guide EBI implementation in community based settings. Although presented as a one-way progression, the Roadmap is not necessarily meant to be followed linearly and steps may need to be continually revisited throughout the implementation process.

Pre-Implementation

\section{Implementation}

\section{Sustainability}

\section{MIP Implementation Roadmap}

Identify high-priority needs

Engage stakeholders

Select essential metrics

Assess contextual factors

Clarify core features

Refine the EBI

Adapt select features to local context
Solicit Feedback and further tailor EBI

Communicate regularly

Maintain engagement

Develop and utilize resources

Support transitions

Collect and monitor key metrics
Analyze and use collected data

Determine cost and establish a return on investment

Establish a business model

Plan to transition ownership to stakeholders 


\section{Figure 1}

MIP Implementation Roadmap. The MIP Implementation Roadmap. Each Phase of the Implementation Roadmap, Pre-implementation, Implementation, and Sustainability, contains generalized stages to guide EBI implementation in community based settings. Although presented as a one-way progression, the Roadmap is not necessarily meant to be followed linearly and steps may need to be continually revisited throughout the implementation process.

\section{Supplementary Files}

This is a list of supplementary files associated with this preprint. Click to download.

- RoadmapPaperlmpSciComChecklist.docx

- RoadmapPaperlmpSciComChecklist.docx 